\title{
Point-of-care ultrasonography for fetal monitoring during non-obstetrical maternal surgery in the second trimester
}

\author{
Neha Singh, MD (D) Chitta Ranjan Mohanty, MD • Bhukya Mohan Nayak, MBBS • \\ Girija Shankar Mohanty, MS
}

Received: 1 February 2019/Revised: 22 February 2019/Accepted: 22 February 2019/Published online: 5 March 2019

(c) Canadian Anesthesiologists' Society 2019

\section{To the Editor,}

Non-obstetrical abdominal surgery during pregnancy involves a multidisciplinary approach by anesthesiology, surgery, obstetrical, and neonatology clinicians. Approximately one in 500 women will require nonobstetrical abdominal surgery during pregnancy. ${ }^{1}$ The most common non-obstetrical surgical emergencies complicating pregnancy are acute appendicitis and cholecystitis, ${ }^{2}$ though other conditions have been reported, including ovarian cysts, masses or torsion, as well as adrenal tumours, splenic disorders, and symptomatic hernias. The American College of Obstetrics and Gynecology Committee suggests that it is important for non-obstetric physicians to obtain obstetrical consultation before performing non-obstetrical surgery, and each case warrants a team approach to optimize safety of the mother and fetus. ${ }^{3}$

Intraoperative fetal heart rate (FHR) monitoring helps to assess fetal well-being. Two methods of intraoperative FHR monitoring are already reported-cardiotocography and ultrasonography with a transesophageal echocardiography probe. ${ }^{4}$ We have used point-of-care ultrasound (POCUS), which has increasingly been reported in the perioperative setting. ${ }^{5}$ Recently, we used POCUS for FHR monitoring during a laparoscopic appendectomy in a second trimester (18 weeks) pregnant patient. An M-Turbo ultrasound machine (Fujifilm SonoSite; Bothell, WA, USA) with a curvilinear 5-2 MHz transducer (using the abdomen software settings) was used via a transabdominal approach. We used it pre-induction (FHR, 143 beats. $\mathrm{min}^{-1}$ ), at the time of

N. Singh, MD $(\bowtie) \cdot$ C. R. Mohanty, MD

B. M. Nayak, MBBS · G. S. Mohanty, MS

All India Institute of Medical Sciences Bhubaneswar,

Bhubaneswar, India

e-mail: anaes_neha@aiimsbhubaneswar.edu.in
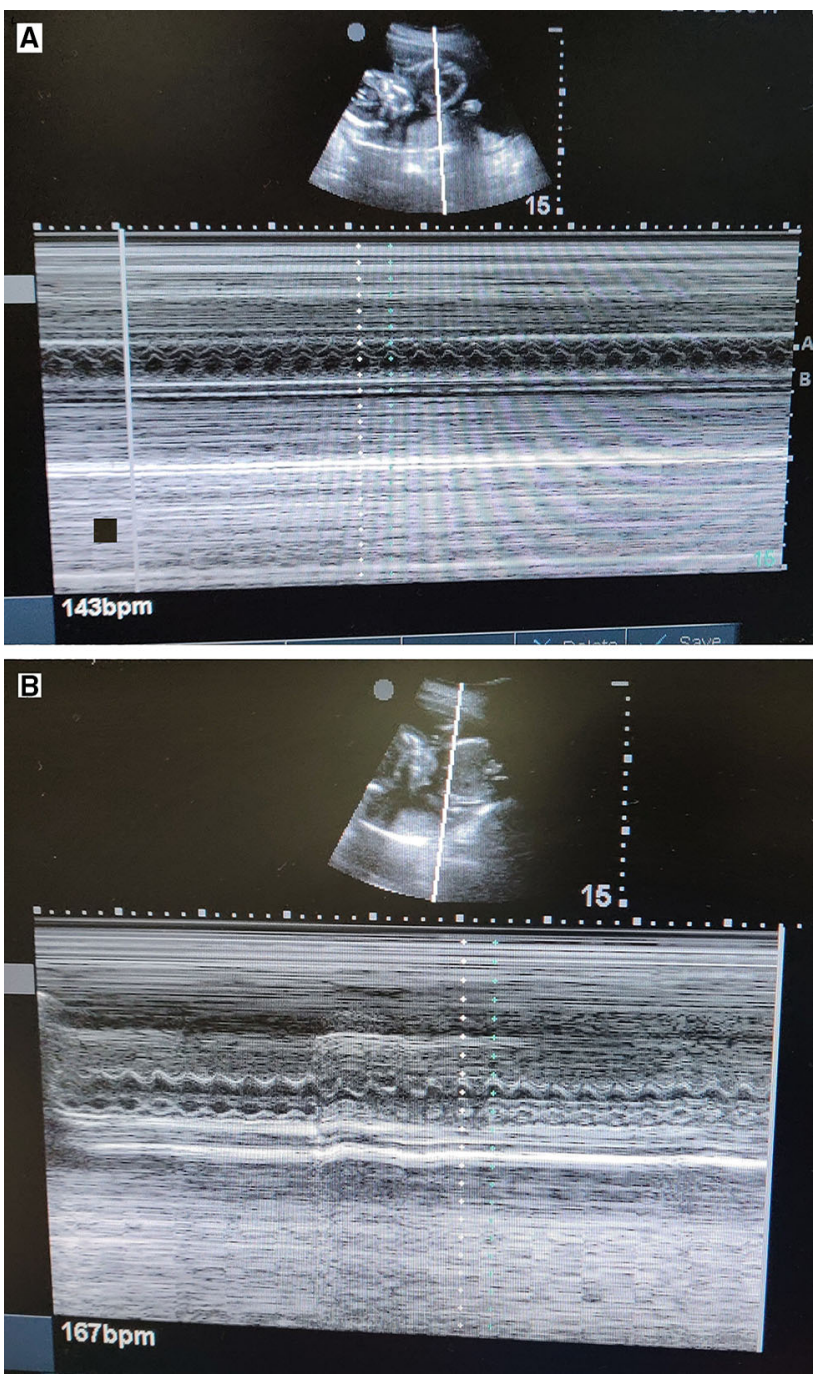

Figure The figure depicts an M-mode point-of-care ultrasound image showing the fetal heart rate before induction (A), and after induction (B) of the pneumoperitoneum. One of the limitations of this method is that it cannot always serve as a continuous monitoring tool because of interference that can occur from the pneumoperitoneum 
pneumoperitonium (FHR, 167 beats $\cdot \min ^{-1}$ ), and then after completion of the surgery (Figure). As anesthesiologists, we need to care for both the mother and fetus, in similar manner to obstetricians. Nevertheless, directing attention to the POCUS of the FHR might distract the anesthesiologist from the care of the mother herself; thus, we suggest that one of the team members should manage the POCUS while others concentrate on taking care of the mother.

Conflicts of interest None declared.

Editorial responsibility This submission was handled by Dr. Hilary P. Grocott, Editor-in-Chief, Canadian Journal of Anesthesia.

\section{References}

1. Pearl J, Price R, Richardson W, Fanelli R; Society of American Gastrointestinal Endoscopic Surgeons. Guidelines for diagnosis, treatment, and use of laparoscopy for surgical problems during pregnancy. Surg Endosc 2011; 25: 3479-92.

2. Augustin $G$, Majerovic M. Non-obstetrical acute abdomen during pregnancy. Eur J Obstet Gynecol Reprod Biol 2007; 131: 4-12.

3. The American College of Obstetricians and Gynecologists. Committee on Obstetric Practice American Society of Anesthesiologists Committee Opinion Number 696, April 2017: Nonobstetric Surgery in Pregnancy. Available from URL: https://www.acog.org/ClinicalGuidance-and-Publications/Committee-Opinions/Committee-on-Obs tetric-Practice/Nonobstetric-Surgery-During-Pregnancy?IsMobileSet= false (accessed February 2019).

4. Fukuda K, Masuoka J, Takada S, Katsuragi S, Ikeda T, Iihara K. Utility of intraoperative fetal heart rate monitoring for cerebral arteriovenous malformation surgery during pregnancy. Neurol Med Chir (Tokyo) 2014; 54: 819-23.

5. McCormick TJ, Miller EC, Chen R, Naik VN. Acquiring and maintaining point-of-care ultrasound (POCUS) competence for anesthesiologists. Can J Anesth 2018; 65: 427-36.

Publisher's Note Springer Nature remains neutral with regard to jurisdictional claims in published maps and institutional affiliations. 